\title{
A review of Small Unmanned Aircraft System (UAS) advantages as a tool in condition survey works
}

\author{
Mohd Fadzil Mat Yasin, Mohd Azian Zaidi ${ }^{1}$ and Mohd Nasrun Mohd Nawi ${ }^{2}$ \\ ${ }^{1}$ Faculty Of Architecture, Planning \& Surveying, Universiti Teknologi MARA Seri Iskandar Campus, Seri Iskandar, 32610 Perak, Malaysia \\ ${ }^{2}$ School of Technology Management and Logistic, Universiti Utara Malaysia.
}

\begin{abstract}
Adoption of new technology in building inspection works has proven to be very crucial and has improved efficiency and effectiveness in this regards. Tools and techniques in building inspection and condition survey continuously evolved trough times. The tools and techniques adopted mostly first has been successfully applied by others technical field such as civil engineering, manufacturing etc.. As UAS has been successfully adopted by many technical professions such as geotechnical engineering, land surveying, civil engineering etc. a practical use of UAV for building surveying and facilities management yet to explored. The present paper intend to explore the viability of UAS application for building inspection with the advantage it has especially in inspecting and collecting data at difficult to reach area such as roof, ceiling, gutter and recording data for large building complex. With the accurate and comprehensive inspection data collected, perhaps it could guide building surveyors or facilities managers in diagnosing building defect effectively, suggesting possible remedies, solving issues and making decision precisely. The present paper provides a comprehensive review of possible application of small UAS in building inspection and facilities management related uses by reviewing the similar application and identifying their features that suits facilities management's nature of practice. Challenges faced by building and facilities management organisation to apply UAS in their building condition survey routine that are identifying suitable tools other than normal visual tools to be attached, finalising arrangement on site during inspection and limited skill of existing personnel to deal with the equipments.
\end{abstract}

\section{Introduction}

The technology of unmanned aerial vehicle was first introduced and successfully exploited by military air forces of few countries in the west since early 1980s [1][2]. Due to its small size and prevailing role, the UAV in the military field also referred as "drone". In the last decades, the technologies are relatively expensive and required highly skilled personnel to operate. However, trough times as the technology evolve; many of the features have been improved. These includes more affordable cost, choices of features and easy to handle. Since then, various industries start to exploit the technology into their field. As cited by Irizarry et. el.,[3], one of the recent cases of using these devices for civilian applications is when a tsunami struck the Fukushima nuclear power plant in Japan on the 11 March 2011. During that disaster, due to very unsafe conditions at the plant, Tokyo Electric Power (TEPCO) used a US-made micro aerial vehicle to photograph the nuclear plant from above.

As it integrates many components the terms Unmanned Arial Vehicle (UAV) has renamed to Unmanned Aircraft System (UAS) [4]. Issues such as stabilisation of flight platform, anti collision, navigation system and route planning algorithms as highlight by several authors for the past few years [1],[2], [3], [5] has been address by new improvement and technology in small UAV and imaging system in recent years.

From facilities management point of view, besides visual inspection, the conventional non-distractive test (NDT) that commonly adopted by the building inspector includes applying test and diagnostic apparatus, thermography and remote sensor technology. Yasin and Egbu [6] contend the performance evaluation of building in which condition survey is being part of it is a very critical task for facilities managers to deal with. A rigours tools and technics therefore are very critical to be deployed. The quality of data collected might help the building inspector to analyse the building performance appropriately.

This paper aims to explore and identify the relevant application of UAS related technology in building inspection by referring to challenges faced by the building inspector in collecting visual data during inspection. The present paper also reviews the similar application of UAS in other part of the globe with the new improvement in UAS technology that could benefit the facilities management organisation in conducting condition survey works. 


\section{Condition survey works}

Condition survey works is a building inspection exercise conducting at specific predetermined intervals and in adhoc basis. The former is conducted as a routine to review the overall performance of the building. The later however is a building inspection conducted focusing on specific elements or assessment for incidents aftermath e.g fire, explosive, disasters. The process of facilities performance evaluation has been extensively discussed by several authors [7]. It could be suggest that three main process which reflect the 'depth' and 'breadth' of the inspection i.e indicative, investigative and diagnostic.

There are very common that the building surveyor have to revisit the site due to accessibility issues and close examines to the particular structure are required. Visual tools such as binocular and distance focused lens alone are sometimes insufficient. In this situation, tools such as suitable leader, scaffolding or even portable hoist need to be hire to reach the high place. This challenge could drag the inspection process for the longer period. As for facilities management operation is concerned, it means the longer period until the defect issues could be solved.

Echmann et al [5] highlight the potential use of UAS in the non-destructive testing (NDT) which includes state detection, damage analysis and condition monitoring. A few examples of potential benefits that could be gain by facilities management team are:

i) saving on time for inspection

ii) minimum number for inspection team

iii) saving on rental of special tools e.g. scaffolding and hoist

iv) risk of height hazard; and

v) quality and reliable onsite data

The building surveyor intent to adopt the UAS in their survey should first aware of the followings:

i) Knowledge and skill - the operator that fly the UAS has at least a basic skill and knowledge to fly the UAS specific model and the camera attached.

ii) Strategy for inspection - determine in which stage of building inspection UAS to be used. Charger and appropriate cameras to be attached to the UAS unit

iii) Whether condition - as the normal UAS unit will only work in a full performance in clear whether condition.

iv) Permission to fly the UAV - any restriction or domestic rules and regulation enforced for UAV. A notice should be given to the parties involve such as the building occupant, public by-passer and neighbouring building owner alerting them about the inspection.

v) A potential hazard to the public and appropriate safety measures

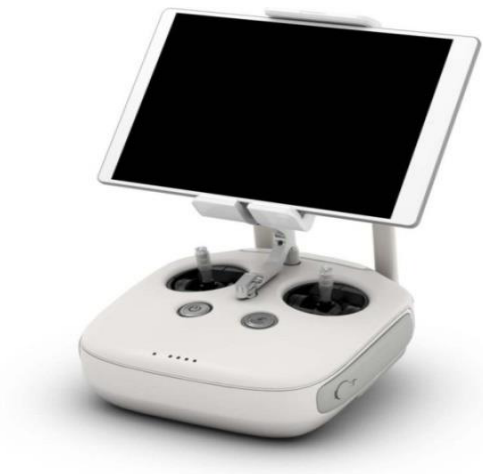

Fugure 1 : Remote Control (RC) unit for Phantom 3 model complete with large display (Internet source : Slashgeer website)[11]

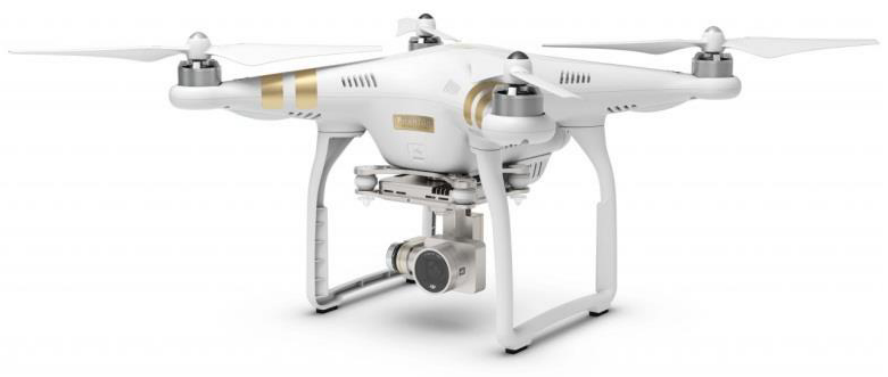

Figure 2 : The Phantom 3 small UAS model (Internet source : Slashgeer website) [11]

The Figure 1 and 2 shows an example of small UAS with 4 exposed propellers available in the market. Various brands and models of small UAS with different technical specification available in the market.

\section{Data collection for condition survey works}

At least, two types of image data that could be collected via this media, which is still image and video graphic image. The building inspector might determined the types and form of image data they required prior the inspection. The selections of the quality camera to be attached to the UAS are critical in order to obtain the quality digital photos and video images. For smooth inspection exercise and limited flight time capability of the UAS, Echmann et. al [5] suggest a preliminary flight track planning by using common software based on GPS waypoint navigation. In order to maintain the sequences of the image taken, a vertical and horizontal movement of the small UAS have to be predefined at flight track planning stage.

\subsection{In-situ still and video image}

Image obtained trough small or micro UAS could provide quick identification of defect spot and type of defect, symptom, causes, and level of severity. Small UAS 
ability to hovering on a specific airspace could provide data on roof such as sign of leakage on roof components i.e gutters, rain water down pipe and roof dome. Other building component that could also be observed are roof tank, roof to chillers, telecommunication antenna and devices etc.

The quality imaging data could be used by on site building inspector to assess the severity of building defect and decide in case further and details information on particular elements are required. For a large building complex, aerial view of the site which shown the site layout, shape and position of the building could be obtained with better quality, details and specific compared to Google maps or Google earth satellite image.

In some circumstances, a more detailed and high definition (HD) imaging are required. Therefore, the available image collected need to be refined and reconstruct in order to satisfy the specific objective of the condition survey works or building inspection.

\subsection{Post flight image reconstruction}

During exploratory roaming by the small UAS, if the defects location are not been identified earlier, a real time image of defect might inform the building surveyor whether or not to get a further and closer look at the specific defect spot.

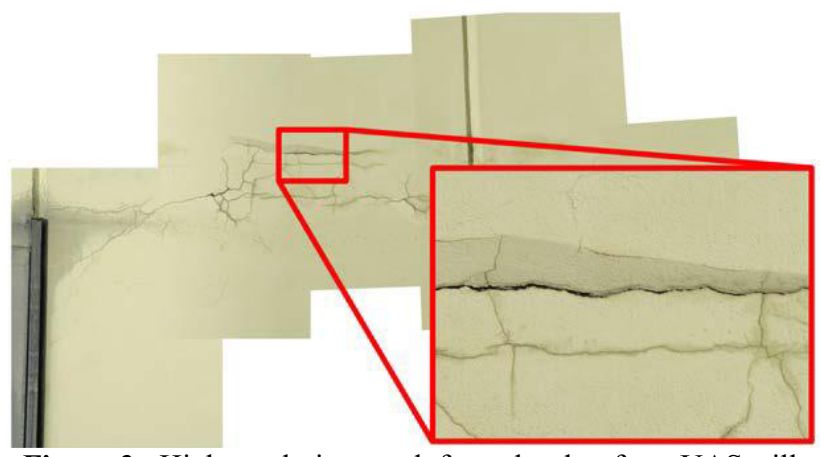

Figure 3 : High resolution crack from the shot from UAS still photograph (source: [5]

A severe and obvious defect identified in the preliminary flight required details visual. The image data could also being enhanced to provide better perspective of the defect. Image of element crack on the upper structure for examples required information such as the other related symptom and trends of the crack need to be observed. In this case, a high definition, extensive and live image are essential.

Building Information Modelling (BIM) might enrich facilities management information repository. A higher resolution image of two or three dimension digital image might help for digital façade reconstruction of BIM system. The visual image captured during the inspection flight could be process and reconstruct after the inspection.

\subsection{Thermal imaging}

The use of thermal imaging for diagnosing building defects was already in place for more than two decades [8] [9] [10]. Similar to UAS technology, the infrared thermal imager was first used in military field and currently been benefited by various other fields as the cheaper market price and advanced of technology [9]. The infrared thermal imaging data could inform the surveyor the causes for building heat loss during winter in four season's country and leaking related defect. The Photo 1 below shows an examples of thermal vision camera for small UAS fitted the bottom side gimbal of the UAS.

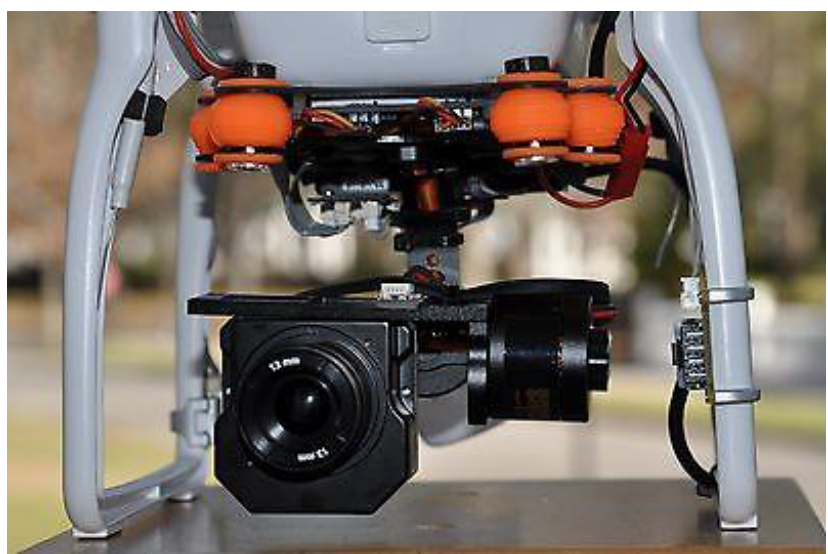

Figure 4: A FLIR VUE Thermal Vision Camera for UAS $7.5 \mathrm{~Hz}(336 \times 256,6.8 \mathrm{~mm}$ Lense) [11]

\section{UAV Specification Consideration}

Before considering the application of small UAS for building inspection, a few considerations should be made by the facilities management organisation. First and foremost obviously the purpose and the scope of building inspection intended for. The purpose of inspection might influence the technical ability of small UAS that match their requirements. Secondly, the budget considerations including UAS initial cost, supporting system, accessories, spare parts and other maintenance expenses. The higher ends UAS unit usually offer a wider range of technological features.

\section{- Flying Range}

No specific range and distance of flight, furthermore, the UAS available in the market are considered sufficient for building inspection purpose. However, to enable takeoff and landing at a narrow platform, the UAS should be from the Vertical Take-off and Landing (VTOL).

- Flying capacity and camera compatibility (and quality)

Gimbals for camera might ensure better quality and clear and image taken during flight.

\section{- Battery life (flying time)}

Battery endurance that could last between 20 40 minutes are considered sufficient with rapid charging battery if need during inspection. Some UAS model has intelligent battery that could return the UAS to the departure point 
automatically one the battery nearly discharged. To avoid interruptions due to unforeseen issues such s absence of power supply at the site, spare battery should also be considered.

\section{-Self-weight and shape}

Due to several reasons such as safety and insurance claim restriction, maximum limit of takeoff weight is nothing more than 5 kilograms. Smaller and lighter the size of UAS could improve the manoeuvre to the difficult space and more practical for building inspection purposes.

\section{Issues and challenges}

Despite the advantage that UAS could offer, there are challenges that hinder building and facilities management to use UAS as one of the tools in building inspection. At least five factor that differ the requirements of one organisation towards UAS:

1) Size of facilities site

2) Floor area

3) Form of buildings

4) Complexity of building structure and building system

5) Nature of building occupation

At this point, it could be hypostasised that the more challenging and comprehensive the facilities is, the higher potential of UAS benefits could be exploited by the building and facilities management organisation. There is also absence of evidence of a formal use of UAS by FM organisation in conducting condition survey.

In the context of present paper, aspect of readiness and awareness of building and facilities management organisation being examine as a preliminary investigation for extensive UAS application in building inspection. For that reason, a sum of 512 questionnaires sent to the building maintenance and facilities management personnel in 159 organisations; the parties that usually conduct building inspection for their parents' organisation or clients depending on their respective service provision. Relatively high response rate with 188 respondents $(37 \%)$ has returned the attached e-mail questionnaire distributed.

Table 1: Ranking of the challenges in applying UAS in condition survey

\begin{tabular}{|c|l|c|}
\hline Rank & \multicolumn{1}{|c|}{ Challenge factors } & $\begin{array}{c}\text { Mean } \\
(\mathbf{N}=\mathbf{1 8 8})\end{array}$ \\
\hline $\boldsymbol{1}$ & Identifying suitable tools (C1) & $\mathbf{1 . 3 2}$ \\
\hline $\mathbf{2}$ & On-site arrangement (C2) & $\mathbf{1 . 8 7}$ \\
\hline $\mathbf{3}$ & Lack of staff (C3) & $\mathbf{1 . 9 6}$ \\
\hline 4 & Lack of awareness (C4) & 2.02 \\
\hline 5 & Familiarity with facilities (C5) & 2.03 \\
\hline 6 & Maintenance of equipments (C6) & 2.19 \\
\hline 7 & Provide training to fly UAS (C7) & 2.32 \\
\hline 8 & Provide training for equipments (C8) & 2.48 \\
\hline
\end{tabular}

$9 \quad$ Cost of equipments (C9)

2.69

Meaning of scale (challenge in conducting FPE):

1 (Very challenging), 2 (Challenging), 3 (Fairly challenging), 4 (Not challenging at all)

The result of mean score in Table 1 indicated as mean score increases, the degree of challenge decreases. An inspection of Table 4.6 shows that facilities managers' ranked "identifying suitable tools to be attached to the UAS system" as most challenging in the survey. As UAS means for collecting buildings data, the limited skill of the personnel in the organisation limiting the benefits and uses of UAS in the building inspection. Site arrangement and insufficient numbers of staff are another key challenge perceived by the building and facilities management personnel on application of UAS as they ranked second and third respectively. Based on the top three challenges related to readiness of building and facilities management personnel indicates that the readiness towards implementation of UAS in their building inspection is at a stumpy level.

Although, acquiring the UAS and equipments including providing training to the staff on using UAS and relevant equipments are less challenge for the organisation as shown on the survey result as they ranked seven, eight and nine respectively, the real potential of UAS application's benefits does not really attentive for them.

The Kruskal-Wallis test was used to identify the significant differences in perceiving the challenges in applying UAS in condition survey (see

Table ) according to three different sizes of building and facilities management organisations. Null hypothesis and alternative hypothesis for the test are as follows:

$\mathrm{H}^{0}=$ the challenges in applying UAS in condition survey differ between sizes of organisation.

$\mathrm{H}^{1}=$ the challenges in applying UAS in condition survey do not differ between sizes of organisation.

\begin{tabular}{llllll}
\hline & C1 & C2 & C3 & C4 & C5 \\
\hline \hline Chi-Square & 6.548 & 10.626 & 2.696 & 6.043 & 1.88 \\
df & 2 & 2 & 2 & 2 & 2 \\
Asymp. Sig. & $.038^{*}$ & $.005^{*}$ & .260 & .051 & .391 \\
\hline & $\mathbf{C 6}$ & $\mathbf{C 7}$ & $\mathbf{C 8}$ & $\mathbf{C 9}$ & $\mathbf{C 1 0}$ \\
& & & & & \\
\hline \hline Chi-Square & 4.376 & 1.159 & 2.015 & 6.508 & 8.04 \\
df & 2 & 2 & 2 & 2 & 2 \\
Asymp. Sig. & .112 & .560 & .365 & $.039^{*}$ & $.018^{*}$ \\
\hline
\end{tabular}

\section{a. Kruskal Wallis Test}

b. Grouping Variable: number of employees

* results are statistically significant at $p<0.05$

Table 2: Kruskal-Wallis test statistic challenge in applying UAS in condition survey according to the organisational size 
Table shows, four out of ten variables indicate the significant value smaller than five per cent. This result informed that, at five per cent level of significance, the null hypothesis is rejected and alternative hypothesis is accepted. This denotes that there is no significant difference in perceiving challenges between the sizes of FM organisations.

\section{Conclusion}

The practical application of UAS has a very broad advantage to facilities management and building surveying team to be exploited. Ground pilot or operator should also aware of few issues related to micro UAS prior deciding to apply them for condition survey exercise. The issues including, safety issues, privacy issues and technical issues. The former issues might involve damage of property, operator itself and third party. Secondly, as the micro UAS use a public air space, a permission and adequate notice should be given to the respective parties. Even though there is absence of clear guidelines by the authorities on flying the UAS, ground pilot should well versed and made clear with allowable space and restriction area for UAS to hover. It could be extrapolates that many more benefits that could be exploited from small UAS technologies in the future in the challenging field of condition survey and facilities management at large.

\section{References}

[1 ]Anand, S., "Domestic use of unmanned aircraft systems: an evaluation of policy constraints and the role of industry consensus standards", ASTM Standardization News, Vol. 35, p. 30. (2007)

[2] Nisser, T. and Westin, C., "Human factors challenges in unmanned aerial vehicles (uavs): a literature review", Lund University School of Aviation, Tech. Rep. TFHS, Vol. 5, p. 1. (2006)

[3] Irizarry, J., Gheisari, M., Williams, G., \& Roper, K.. Ambient intelligence environments for accessing building information: A healthcare facility management scenario. Facilities, 32(3/4), 120138. (2014)

[4] International Civil Aviation Organization ICAO Cir 328, Unmanned Aircraft Systems (UAS), Quebec, Canada. (2011)

[5] Eschmann, C., Kuo, C. M., Kuo, C. H., \& Boller, C. Unmanned aircraft systems for remote building inspection and monitoring. In 6th European workshop on structural health monitoring. (2012)

[6] Yasin, F., \& Egbu, C. O. Exploitation of knowledge mapping benefits in the facilities performance evaluation process: a conceptual framework. In Procs 26th Annual ARCOM Conference (pp. 799808). Association of Researchers in Construction Management. (2010)

[7] Yasin, F, The Contribution of knowledge mapping in facilities performance evaluation practice in Malaysia, The University of Salford, $\mathrm{PhD}$ thesis, not published (2013)
[8] Titman, D. J. Applications of thermography in nondestructive testing of structures. NDT \& E International, 34(2), 149-154. (2001)

[9] Balaras, C. A., \& Argiriou, A. A. Infrared thermography for building diagnostics. Energy and buildings, 34(2), 171-183. (2002)

[10] Grinzato, E., Bison, P. G., \& Marinetti, S. Monitoring of ancient buildings by the thermal method. Journal of Cultural Heritage, 3(1), 21-29. (2002)

[11] Slash Geer website : http://www.slashgear.com/djiphantom-3-drone-revealed-with-newly-choppedprice-points-08377962/ extracted on 15/1/2016

[12] Hallermann, N., Morgenthal, G., \& Rodehorst, V. Vision-based monitoring of heritage monumentsUnmanned Aerial Systems (UAS) for detailed inspection and high-accurate survey of structures'. Proceedings of STREMAH, 621-632. (2015) 